\title{
ARTIGOS
}

\section{Ideologia e Prática do Planejamento Durante o Estado Nôvo*}

\author{
Octavio lanni**
}

E muito provável que a técnica de planejamento, enquanto instrumento de política económica estatal, tenha começado a ser incorporada pelo poder público, no Brasil, durante a segunda guerra mundial (1939-45). Ao menos, foi nessa época que a planificação passou a fazer parte do pensamento e da prática dos governantes, como técnica mais racional de organização das informações, análise de problemas, tomada de decisóes e contrôle da execução de politicas económico-financeiras. De fato, nesses anos discutiram-se (em âmbito governamental e empresarial, em têrmos técnico-científicos e políticos) a conveniência, os limites $\theta$ os riscos da adoção dessa técnica. Analisaram-se, então, os argumentos relacionados com questões tais como as seguintes: a crescente interferéncia es-

* Capitulo de uma obra, em elaboração, sóbre estratégias políticas do desenvolvimento económico brasileiro, nos anos 1930-1970. Essa obra faz parte do programa de pesquisas do Centro Brasileiro de Análise e Planejamento (CEBRAP).

* Livre-docente pela Universidade de Săo Paulo e membro do CEBRAP - Centro de Análise e Planejamento.

R. Adm. Emp., Rio de Janeiro, tatal nas decisões sóbre assuntos económicofinanceiros; a adoção e a elaboração da política económica governamental planificada; o papel do poder público na criação de condições (financeiras, técnicas, jurídicas, etc.) para a expansão e a diversificação do setor privado da economia do pais; as novas exigências econômicas da defesa nacional. Não se pense, todavia, que êsses problemas foram propostos de uma só vez e em nivel teórico. Ao contrário, éles se colocaram de modo desordenado e em função de dilemas práticos. A verdade é que medidas de tipo intervencionista já eram adotadas pelos governantes brasileiros nas décadas anteriores a 1930. Desde o principio do século vinte, o poder público passara a adotar diretrizes cada vez mais elaboradas e técnicamente mais rigorosas para fazer face a problemas, tais como os seguintes: proteger ou estimular os setores económicos já instalados da economia nacional; formalizar o mercado de fatôres da produção; e, também, controlar as relaçōes sociais de produção. Nessa linha de atuạ̧ão,

11(1): $7-15$

Jan./Mar. 1971 
foram postas em prática, com maior ou menor sucesso, as seguintes politicas governamentais: plano de recuperação econômico-financeira, do govêrno Campos Salles (18981902), conduzido por seu ministro da Fazenda, Joaquim Murtinho; plano de defesa e valorização do café, segundo os têrmos do Convênio de Taubaté (1906), formulado pelos governos dos estados do Rio de Janeiro, Minas Gerais e São Paulo; vários planos de obras contra as sêcas, realizados principalmente pelos governos federais, desde o princípio do século vinte; legislaçāo trabalhista, para disciplinar, controlar e reprimir as reivindicaçōes econômicas, sociais e políticas do nascente proletariado. Além dessas atividades, os governantes brasileiros solicitaram (ou aceitaram) as missões inglêsas chefiadas por Edwin Montagu (1923) e Otto E. Niemeyer (1931), as quais analisaram a situação econômico-financeira do Brasil e fizeram recomendações de política orçamentária, financeira e econômica. Em boa parte, tratava-se de salvaguardar os interèsses inglêses no comércio com o Brasil. Aliás, paralelamente às realizações do poder público brasileiro, já vinham sendo debatidos, também, o protecionismo alfandegário, para o nascente parque manufatureiro, e o intervencionismo estatal. Em outros têrmos, desde o comêço do século vinte debatiam-se e combatiam-se as politicas econômicas governamentais inspiradas ou influenciadas pela doutrina liberal. 1

Essa foi a experiéncia acumulada nas décadas anteriores à revolução de 1930. Não

1 Quanto às relaçóes entre 0 poder público 0 sistema económico, durante a segunda metade do século dezenove, merece destaque especial a polítlca imigratória levada a efeito sob a orientaçăo do governo central, em cooperaçăo com cafeicultores e governos provinciais (e estaduals, depois da Proclamaçăo da República). Consultar: Prado Júnior, Calo. História económica do Brasill. $3^{a}$ ed., Săo Paulo, Editóra Brasiliense. 1953, cap. 19; Furtado, Celso. Formaçăo económica do Brasil. $7^{\mathrm{a}}$ ed., Companhia Editôra Nacional, 1967, quarta parte; Octavio lanni, Sérgio Buarque de Holanda, Teresa Schorer Petrone e Carlos H. Oberacher Jr., na obra organlzada por Buarque de Holanda, Sérgio. O Brasil monárquico. v. 3, Săo Paulo, Dlfusão Europé:a do Livro, 1957. Livro Segundo; Costa, Emilia Viottl da, Da senzala à colónia. São Paulo, Difusão Européla do Livro, 1966, esp. primeira parte. se pense, todavia, que as relações entre o estado e a economia alteraram-se de modo repentino e completo. Houve marchas e contramarchas, nos anos que se sucederam à revolução. Entretanto, a despeito das ambigüidades ideológicas e práticas de governantes, empresários e técnicos (responsáveis pela formulação, execução e contrôle da política econômica governamental), o poder público foi levado a participar de modo cada vez mais amplo e sistemático na economia do país. É - que transparece também nas constituições brasileiras de 1934 e 1937.

Note-se que as constituiçōes de 1891 e 1926 eram bastante influenciadas pela doutrina liberal, tanto $\mathrm{ccm}$ referência à noção de democracia representativa como quanto às relações entre o poder público e as atividades econômicas. Assim, por exemplo, a Constituição de 1891 estabelecia que "as minas pertencem aos proprietários do solo" (art. 72, § 17). Na Constituição de 1926, no entanto, já se introduz uma restrição. Continua válido o principio de que as minas pertencem ao proprietário do solo, mas fica estabelecido que "as minas e jazidas minerais necessárias à segurança e defesa nacionais e as terras onde existirem não podem ser transferidas a estrangeiros" (art. 72, § 17). Na Constituição de 1934, por seu lado, adotaram-se explicitamente os principios nacionalista e intervencionista, em contraposição à orientação liberal das constituições anteriores.

"O aproveitamento industrial das minas $e$ das jazidas minerais, bem como das águas e energia hidráulica, ainda que de propriedade privada, depende da autorização ou concessão federal, na forma da lei.

$\S 1$ : As autorizações ou concessões serão conferidas exclusivamente a brasileiros ou a emprêsas organizadas no Brasil, ressalvada ao proprietário preferência na exploração ou co-participação nos lucros. (...) $\$ 4$ \% A lei regulará a nacionalização progressiva das minas, jazidas minerais e quedas d'água ou outras fontes de energia hidráulicas, jul- 
gadas básicas ou essenciais à defesa econômica ou militar do pais. (Constituiçăo de 1934, art. 119).

A Constituição de 1937, por fim, outorgada pela ditadura instituída com o Estado Nôvo, sob Getúlio Vargas, manteve as mesmas diretrizes nacionalista $\theta$ intervencionista. Foi, entretanto, mais explicita, ao enunciar a possibilidade de atuação do poder público em qualquer esfera da economia.

"A intervenção do estado no domínio econômico só se legitima para suprir as deficiências da iniciativa individual e coordenar os fatôres da produção, de maneira a evitar ou resolver os seus conflitos e introduzir no jôgo das competições individuais - pensamento dos interésses da nação, representados pelo estado.

A intervenção no domínio econômico poderá ser mediata $\theta$ imediata, revestindo a forma do contrôle, do estímulo ou da gestão direta." (Constituição de 1937, art. 135).

Como se depreende désse texto constitucional, em 1937 o estado estava sendo preparado para assumir funções económicas mais complexas $\theta$ ativas. ${ }^{2}$ Note-se a reféréncia explicita aos seguintes problemas: a possibilidade de gestão direta, por parte do poder público; as "razóes de estado" impondo-se sobbre os conflitos entre capital e trabalho, para defender os interêsses superiores da nação; e a necessidade de estabelecerem-se as normas adequadas ao funcionamento mais

2 Note-se que durante os anos 1930-45 o govêrno federal criou, entre outros orgăos ligados ao sistema económico nacional, os seguintes: Conselho Nacional do Café, em 1931; Ministério do Trabalho, Indústria e Comércio, em 1930; Conselho Federal do Comércio Exterior $\theta$ Instituto Nacional de Estatístlca, em 1934; Conselho Técnico de Economia e Finanças, em 1937; Conselho Nacional do Petróleo e Departamento Administrativo do Serviço Público (DASP), em 1938; Comissão de Defesa da Economia Nacional $\Theta$ Fábrica Nacional de Motores, em 1940; Companhla Siderúrgica Naclonal, em 1941; Servlço Nacional de Aprendizagem Industrlal (SENAI), em 1942; Coordenaçăo da Mobilizaçăo Económica, Companhia Nacional de Alcalis, Usina Slderúrgica de Volta Redonda, Consolidaçăo das Lels do Trabaiho e Plano de Obras e Equlpamentos, em 1943; Conselho Naclonal de Politica Industrial e Comerclal, em 1944; Superintendéncia da Moeda $*$ Crédlo (SUMOC) - Decreto-iel ne 7.666, sobre atos contrárlos a ordem económica, em 1945. eficiente do mercado de capital e fôrça de trabalho, isto é, os fatôres da produção. Essas foram, em boa parte, as razōes que inspiraram a criação do Conselho da Economia Nacional, no âmbito da própria Constituição de 1937. Isto é, o mesmo govérno que conferira novas funçŏes económicas ao estado, criara um órgāo destinado a colhêr dados, realizar estudos, emitir pareceres sobbre projetos de iniciativa governamental $\theta$ apresentar recomendaçōes para as políticas agrícola, industrial, comercial, de transportes, financeira, administrativa, trabalhista e educacional. Composto por representantes dos vários ramos da produçăo (empregadores e empregados), o Conselho da Economia Nacional tinha ainda como atribuiçăo:

“Organizar, por iniciativa própria ou proposta do govêrno, inquérito sóbre as condições do trabalho, da agricultura, da indústria, do comércio, dos transportes e do crédito, com o fim de incrementar, coordenar $\theta$ aperfeiçoar a produção nacional." (Art. 61).

A verdade é que o estado era levado a atuar sempre que surgiam as crises economicas, financeiras e trabalhistas. A medida que se expandiam o setor terciário urbano e a industrialização incipiente, aumentava a classe média, o proletariado e a burguesia industrial. Em conseqũência, surgiam novos interêsses éconómicos, sociais e políticos. Conforme se intensificava a divisão social do trabalho e diversificava-se a sociedade urbana, o estado era levado a defrontar-se com problemas e dilemas novos e, multas vézes, mais complexos.

Essas relaçōes e correspondéncias entre as transformaçōes da sociedade e do estado (como componentes do mesmo sistema global) manifestavam-se de modo aberto nas situações de crise. E a segunda guerra mundial produziu uma crise particularmente profunda no conjunto do sistema económico e político.

No nivel do sistema económico e fimanceiro, a guerra mundial de 1939-45 colo- 
cou o Brasil diante de problemas tais como os seguintes: a) caíram repentinamente as exportaçőes de café, cacau, madeira, laranja, banana, etc., devido ao isolamento dos mercados externos mais importantes. Em conseqüencla, cresceram desmedidamente os estoques e baixaram os preços; b) tornaram-se escassos os produtos importados, tais como carvão, gasolina, óleo combustivel, máquinas, metais etc.; c) cresceu rápidamente a demanda de material bélico ou importante para a mobilizaçăo militar; d) verificou-se uma onda inflacionária, com o agravamento da situação econômica $\theta$ social dos assalariados urbanos, particularmente o proletariado. Essa inflação toi impulsionada pelo crescimento das despesas governamentais e pelo acúmulo de divisas provenientes das exportaçőes de suprimentos de guerra para os Estados Unidos e a Ingiaterra. Em regime de contrôle cambial (numa época em que a importação não compensava a exportação) o govérno brasileiro era obrigado a transterir grandes quantidades de moeda nacional aos exportadores. Em conseqüência, crescia mais que proporcionalmente a demanda no mercado interno.

Esses foram alguns dos principais problemas diante dos quais os governantes $e$ os grupos económicos interessados precisaram agir com rapidez. A guerra mundial criara, também no Brasil, uma economia de guerra. A queda e transformaçăo do comércio internacional geraram problemas económicos, financeiros, tecnológicos, organizacionais, sociais e políticos, diante dos quais o estado foi levado a atuar de modo mais ou menos profundo, conforms o caso.

3 Prado Júnior, Calo. Op. cit. especialmente páginas 305-319; Economia de guerra no Brasll 10 que Iez a Coordenaçio da Mobllizagto Económica). Rio de Janeiro, Imprensa Nacional, 6 v., editados nos anos de 1946 a 1948; A misalio Cook no Brasll. Relatório dirigido ao presidente dos Estados Unidos da América pela Missấo Técnica Americana enviada ao Brasil, traduzido e editado pela Fundaçåo Getúllo Vargas, Rlo de Janeiro, 1949; Harris, Seymour E. Problemas económicos da Amórica Latina. Traduçăo de Adolfo Alvarez Buyila. México, Fondo de Cultura Económica, 1945. esp. p. 292-323.
Esse fol o contexto em que se criou, em 1942, a Coordenaçăo da Mobilizaçăo Económica. Durante os anos da guerra, ésse orgão governamental teve (não só formalmente) o caráter de um verdadeiro superministério. Por seu intermédio, o govêrno coordenava assuntos económicos, financeiros, tecnológicos e organizacionais da economia nacional, considerada como a economia de um pais em estado de guerra. Por isso a Coordenaçăo absorveu boa parte das atribuiçóes do Conselho Federal de Comércio Exterior. Para térmos uma idéia da amplitude das atribuiçōes $\bullet$ prerrogativas do coordenador da Mobilização Económica (uma espécie de superministro), vejamos o que se estabelecia no decreto-iei que instituiu o órgão.

"Ao coordenador da Mobilização Econômica, como delegado do presidente da República, competem, em geral, as atribuiçס̃es de coordenação indispensável para: 1 . orientar a mineraçáo, a agricultura, a pecuária a Indústria em geral, no sentido de habilité-las a produzir, com a máxima eficiencia, os materiais a produtos mais necessários e urgentes; 2 . controlar, através da Carteira de Exportação e Importação do Banco do Brasil, a importação e a exportação de matérias-primas, produtos semimanufaturados a manufaturados, atentendo às conveniéncias e necessidades das fôrças armadas, do serviço público $\theta$ do povo em geral; 3. coordenar os transportes no território nacional e para o exterior; 4 . planejar, dirigir e fiscalizar o racionamento de combustiveis e energia; 5 . intervir no mercado do trabaiho, determinando a utilização de măo-de-obra, no tempo e no lugar próprios; 6. investigar o custo, os preços e os lucros das mercadorias, materiais e serviços; 7. fixar os preços máximos, minimos e básicos, ou os limites de preço pelos quals as mercadorias ou materiais devem ser vendídos ou os serviços devem ser cobrados; 8. proibir a compra, venda ou fornecimento em base diferente dos preços fixados; 9 . determinar as condiçбes 
de venda de mercadorias; 10 . exigir dos produtores, fabricantes e demais negociantes e fornecedores de mercadorias as licenças que se fizerem necessárias; 11 . fixar ou limitar a quantidade de qualquer mercadoria a ser vendida, fornecida ou distribuida ao consumo público, bem como dos serviços a serem prestados; 12 . levantar $\theta$ coordenar dados estatisticos relativos a preços, custos e estoques de mercadorias; 13. estudar $\theta$ propor qualquer medida tendente a assegurar a defesa da economia da nação." 4

Em seguida, o coordenador, João Alberto Lins de Barros, tomou as medidas indispensáveis para que se concretizassem as finalidades $\theta$ as funções da Coordenação da Mobilização Económica. Assim, dentre os setores em que atuou ésse órgão, incluiu-se tanto a mobilização de trabalhadores para os seringais da Amazónia como a fixação do salário mínimo, para as diferentes regióos do país. 5 Dentre os órgãos criados pela Coordenação, cabe uma referência especial ao Setor da Produção Industrial (S.P.I.). Conforme se depreende dos têrmos com que se definiram as suas atribuiçōes, tratava-se de um órgão destinado a planejar o funcionamento - a expansão do setor manufatureiro.

"Ao S.P.I. cabe: a) elaborar a planificação industrial do país, de modo a atender às suas necessidades militares $\theta$ civis $\theta$ possibilitar a sua colaboração no esfórço de guerra dos palses aliados; b) orientar, dirigir e controlar o programa de produção industrial do país, para isso determinando, quando necessário, a instalação, mobilização, transformação e adaptação de fábricas; c) estudar $\theta$ fixar as prioridades na distribuição para a indústria de combustiveis, energia elétrica, matérias-primas,

4 Decreto-lel $n 94.750$ de 28 de setembro de 1942 , art. 3P. Cf. Martins Gomide. A coordenaģa conómica - sua leglalaçăo. Rlo de Janeiro, Ediçlo do autor, Op. cit. p. 87-88 e 113-119.

5 Cf. Portaria $n^{\circ} 28$, de 30 de novembro de 1942 e Portaria n ${ }^{\circ} 36$, de 8 de janelro de 1943. Martins Gomide. Op. cit. p. 87-88 e 113-119. transportes $\theta$ måo-de-obra; d) estudar $\theta$ organizar a produçăo em série de produtos, - bem assim a sua simplificação e padronização quando forem julgadas necessárias; e) realizar pesquisas e estudos tócnicos $\theta$ económicos que forem julgados necessários; f) promover a formaçăo de técnicos especializados para a indústria; g) dar assisténcia técnica indústria e realizar o controle de sua eficiencia quando julgar necessário." -

Como vemos, pouco a pouco a idéia e a prática da planificaçáo são incorporadas à politica económica governamental. Isto $\dot{e}$, pouco a pouco criaram-se novas condiçס̃es para a formaçăo e o desenvolvimento de uma espécie de tecnoestrutura estatal no Brasil. 7 A verdade é que as mesmas crises e transformaçס̃es que afetavam o sistema económico-social - polftios tes quals puseram em evidencia as limitaçoos do subsistema capitalista brasileiro) criaram também as condições para a elaboração de novas técnicas de ação. Aliás, o próprio debate adquiriu novos conteúdos. Passou-se inclusive a formular e discutir estratégias políticas em relação com os problemas do desénvolvimento económico. Colocou-se na ordem do dia, por exemplo, o problema da democratizaçăo, em relação com a economia e o esfórço de guerra. Ou seja, recolocou-se a problemática das relaçōes entre o poder politico e o poder econômico.

Foi nessa sequéncia de acontecimentos $\theta$ idéias que se propuseram as teses $\theta$ os debates do 1 Congresso Brasileiro de Economia, realizado em 1943, no Rio de Janeiro. Nesse congresso, cuja presidéncia de honra

\footnotetext{
- Portaria ni 21, da Coordenaçăo da Mobillzaçăo Económica. Cf. Martins Gomide. Op. cit. p. 65-67. Com relaçăo aos problemas do setor Industrial, consultar: Economia de guerre no Braell, cltada, esp. v. 4 5 .

7 o conceito de tecnocracla năo nos parece convenlente à análise que estamos desenvolvendo, pelas seguintes razós: a) envolve a idéla de governo ou regime em que predominam os tócnicos, isto $e$, uma determinada elite, independentemente do jogo politico dos partidos, das relaçoes de classes etc.; b) traz consigo a Idéla de que a tócnica, em sentido lato, uma varifival independente $\theta$ predominante.
} 
coube ao ditador Getúlio Vargas, reuniram-se comerciantes, industriais, banqueiros, agricultores, economistas, funcionários do govêrno, professôres universitários e técnicos. 8 Conforme lembrou na ocasião o presidente efetivo do congresso, João Daudt d'Oliveira, todos deviam reconhecer que "a politica e a economia são interdependentes". E acrescentou:

"Não é sòmente participando das honrosas posiçōes de govêrno que os comerciantes, os industriais, os agricultores, edificam a riqueza da nação.

Eles verificam que por tóda a parte os postos de direção em grande escala lhes estão sendo confiados, por um conjunto de circunstâncias a que se curvam os governos bem inspirados.

O caráter social da função comercial acarretou uma nova situação para todo aquéle que de uma mesa de trabalho dirige fábricas, planeja operações agrícolas ou encabeça transações: tornou-o parte de uma grande ação política - a política económica do seu pais.

Aos governos cabe coordenar, de um plano superior, os elementos dispersos dessa obra, e nisso está justificada a necessidade da participação dos representantes da produção em seus conselhos e gabinetes técnicos.

Será impossível, porém, qualquer intervenção construtiva no terreno econômico, na esfera de ação privada, se não houver um sentido comum dominando espiritualmente as atividades de cada chefe-de emprésa. E imprescindivel a existéncia de uma polftica económica na consciéncia de todos, que represente a última decisão para os seus conflitos de interésses, $\theta$ também o

8 O congresso contou com 234 membros, os quais representavam 192 entldades $\theta$ apresentaram 94 toses sóbre os mais diversos problemas nacionals. Dentre os membros do conclave, encontravam-se Roberto Simonsen, Gastăo Vidigal, Eugénio Gudin, Octavio Gouvea de Bulhoes, Glycon de Paiva, Gileno de Carll e outros, além de Euvaldo Lodi, entáo presidente da Confederaçăo Nacional de Indústria, Joâo Daudt d'Olivelra, presidente da Federaçăo das Associaçסes Comercials do Brasil. maior dos interesses em meio às suas decisões.

A vantagem do país está em que os fatos decorram dentro de uma certa harmonia relativa, onde os pequenos dissidios se acomodem continuamente, como se pequenas estruturas, sempre em formação, se acertassem dentro da grande estrutura nacional. Dessa constante acomodação surgirá um movimento de conjunto, cujo benefício 80 poderá chamar de prosperidade coletiva, progresso nacional ou crescimento do nivel económico da vida." "

A verdade $a$ que empresários, governantes, economistas e técnicos estavam reunidos para fazer um balanço das condiçōes e perspectivas da economia brasileira. Por um lado, tratava-se de estudar os dilemas criados com a própria economia de guerra. Ou melhor, tratava-se de aprimorar a consciéncia então possivel dos limites $\theta$ possibilidades evidenciados pelo drástico declínio $\theta$ reorientaçăo do comércio externo. Nesse sentido, Roberto Simonsen disse o seguinte, no mesmo congresso:

"A guerra veio pór em destaque, de um lado, a interdependéncia económica dos povos, $\theta$, de outro, a profunda diversidade da sua capacidade material de agir ou reagir, em função da relativa possança de seus aparelhamentos económicos (...).

- Hoje, a técnica, a ciência e a política econômica já nos indicam os meios capazes de fixar os fatôres que nos conduzirão às mais rápidas $\theta$ apropriadas realizaçōes, conducentes ao nivel de grandeza que necessitamos atingir." 10

Por outro lado, tratava-se de delinear diretrizes para a política económica das emprêsas e do govêrno. Os empresários, membros do govêrno, economistas e técnicos reu-

9 Discurso de Jollo Daudt d'Oliveira. Cf. Anais do 19 Congresso Brasileiro de Economia reailzado no Rlo de Janeiro, de 25 de novembro a 18 de dezembro de 1943, Rilo de Janeiro, 1943. v. 1, p. 63-78; cltaçăo da p. 71 .

10 Discurso de Roberto Simonsen. Cf. Anals. Cltado. p. 91-96; citaglo das p. 92 - 94. 
nidos no congresso julgaram conveniente e necessário apelar ao poder público, para que êste se colocasse (de modo mais direto, amplo e ativo) no centro das decisões relativas a economia do país. Com êsse objetivo, formularam recomendações a propósito da economia brasileira em geral; bem como sóbre a indústria, agricultura, comércio, exportação, importação, finanças, câmbio, desequilibrios regionais, salário, sindicalismo e bem-estar social. Quanto ao desenvolvimento industrial, por exemplo, as conclusões e recomendações dos congressistas foram claras. Assim, tendo em conta que os problemas e os desenvolvimentos da economia brasileira revelavam a necessidade $\theta$ as vantagens de uma rápida e eficiente industrialização, recomendava-se:

"Que se intensifique, mediante uma definida política industrial, a industrialização do país, já iniciada sob tão favoráveis auspícios. (...)

Que se sugira ao governo federal a conveniência de serem as indústrias básicas organizadas, na falta de iniciativas particulares, com a participação do estado, ou com - seu amparo. O estado, neste caso, participará da sua administração, ou tabelará os seus produtos, mediante fiscalização adequada, de modo que concilie o incentivo devido à produção com os interêsses dos consumidores." 11

Esse foi o contexto (aliás bastante desenvolvido pela situação de guerra) em que surgiram, mais agudas, as novas exigências de racionalização dos meios e técnicas de coleta de dados, sistematização, análise e decisão sôbre problemas de política econômica $\theta$ administração. Em conseqüência, surgiu uma nova figura na esfera das organizaçōes que se estavam elaborando, para fazer face às novas exigências da política econó-

\footnotetext{
11 Cf. Anais. Citado, p. 144 e 145-8.

12 Cohn, Gabriel. Problemas da industrialização no século $X X$. Brasll em perspectiva, citado, p. 317-353; citaçăo da p. 336. A propósito da mesma probiemática, consultar: Cohn. Gabrlel. Petróleo - naclonaliamo. Săo Paulo, Difusão Européla do Livro, 1968.
}

mica. Conforme análise realizada por Gabriel Cohn, sóbre a mesma problemática:

"A característica mais marcante dêsse período todo, ao lado do aumento geral de importância dos grupos sociais urbanos, é dada pela emergência de uma nova tigura, - que desempenharia papel de relévo no esforrço industrializante até 0 presente: 0 assessor técnico, tanto a serviço do govêrno quanto das entidades privadas. $\mathrm{Na}$ realidade, a ação désses elementos se revelaria capaz de contrabalançar em boa medida - relativo tracasso das reformas do aparelho administrativo estatal encetadas na epoca." 12

Essas preocupações com a técnica e a prática do planejamento, enquanto elemento da política económica governamental, acentuam-se ainda mais no ano seguinte (1944), quando se tornou mais clara a perspectiva de término da guerra mundial. Então, os governantes e empresários propuseram-se esclarecer os seguintes problemas de estratégia de desenvolvimento:

"Se a nossa evolução económica já estabeleceu princípios fundamentais que devam orientar 0 desenvolvimento industrial e comercial do Brasil no futuro.

Se é possível organizar uma classificação, em ordem decrescente, das indústrlas merecedoras de proteção, em vista de suas possibilidades de éxito e permanéncia perante a concorrência estrangeira." 13

Em face dessa problemática, isto é, das perspectivas e dilemas criados com a segunda guerra mundial e a mobilização económica do Brasil, Roberto Simonsen considerou que o setor privado não estava preparado para fazer face às novas exigéncias de capital, tecnologia, know-how, capacidade de organizaçăo, liderança etc. Por isso, as novas perspectivas de desenvolvimento econó-

13 Marcondes Filho, Alexandre. Indicaçüo n. 9, 5 de abril de 1944, apresentada ao Conselho Nacional de Política Industrial e Comercial, do Ministério do Trabalho. indústrla e Comércio. Ct. Conselho Nacional de Política Industrial e Comerclal. A planificaçăo da economia naclonal. Rio de Janelro, Imprensa Naclonal, 1945. p. $9-10$. 
mico e, em especial, industrial exigiam a formulação e utilização de novos instrumentos de ação, incluindo-se o planejamento e o pensamento técnico-cientifico.

"Impōe-se, assim, a planificação da economia brasileira em moldes capazes de proporcionar os meios adequados para satisfazer as necessidades essenciais de nossas populaçōes e prover o país de uma estruturação económica e social, forte e estável, fornecendo à nação os recursos indispensáveis à sua segurança o à sua colocação em lugar condigno, na esfera internacional.

A ciência e a técnica modernas fornecem seguros elementos para o delineamento dessa planificação. Haja vista o que se féz na Rússia e na Turquia, quanto ao seu desenvolvimento material; considerem-se as planificações levadas a efeito pelos Estados Unidos, pela Inglatera e por outros paises em luta, para organizar as suas produções, dentro de um programa de guerra total. (...)

O grau de intervencionismo do estado deveria ser estudado com as várias entidades de classe, para que dentro do preceito constitucional fósse utilizada, ao máximo, a iniciativa privada e não se prejudicassem as atividades já em funcionamento no pais, com a instalação de novas iniciativas concorrentes. Proporcionar-se-iam, ao mesmo tempo, os meios indispensáveis à renovação do aparelhamento existente." 14

Diante dessas sugestōes, apresentadas no Conselho Nacional de Politica Industrial e Comercial, em 1944, houve uma reação imediata, de tipo liberal. Eugénio Gudin, que liderou essa reação, defendeu a privatização da economia, a livre participação do capital estrangeiro e a neutralidade do poder público. Isto é, que o estado deveria apenas "estabelecer as regras do jógo" e não interferir nas atividades económicas. Nessa linha de

14 Simonsen, Roberto C. O pianejamonto da economia brasileira (Répllca ao Sr. Eugénio Gudin; na Comissăo de Planejamento Económico). Sťo Paulo, ediçăo do autor, jun. de 1945. p. 25 @ 98 . raciocínio, propugnou a privatização da indústria siderúrgica estatal.

"Uma vez reduzido o capital da Companhia Siderúrgica Nacional a cifras compativeis com sua produtividade, deveriamos tratar de vender ao público as ações de propriedade do govêrno, permitindo ao capital estrangeiro uma participação de 30 a $40 \%$." 15

Mas ésse dobate a propósito das funçठ̋es do estado na economia nacional nāo se encerra nem nessa época nem nesse nivel. Continuará nos anos posteriores. A verdade é que estava em jógo uma nova fase da oconomia brasileira. E aquêle debate simbolizava as novas fórças políticas e económicas em confronto no país. O término da guerra o a chamada redemocratizaçăo do país estavam incluindo novos problemas e novos grupos sociais no debate relativo às estratégias políticas de desenvolvimento. Além disso, as próprias tarefas práticas do poder público exigiam decisões imediatas $\theta$, às vêzes, inovadoras. E a experiência já acumulada, no campo das relaçóes entre o poder público e as atividades económicas, demonstrara a conveniência de maior coordenação da política económica governamental. Por isso, em 1945, os empresários, membros do govêrno, economistas e-técnicos, novamente reunidos em conferência sóbre as condições e perspectivas da economia brasileira, reconhecem no planejamento uma técnica de aceleração do desenvolvimento econômico.

"É sua opinião que o Brasil, necessitando urgentemente de recuperar o tempo perdido para atingir a renda nacional necessária a permitir a seu povo um melhor nivel de vida, procure acelerar a evolução de sua economia por meio de técnicas que lhe assegurem rápida expansāo. Para isso,

15 Gudin, Eugênio. Rumos da politica econômica. Rlo de Janeiro, 1945. p. 56. Cf. cltaçăo de Simonsen, Roberto. Op. clt. p. 40. Quanto a esse debate, consultar também: Almeida Magaihăes, Jožo Paulo de. Controvérsia braslleira sobbre o desenvolvimento econsmico. Rio de Janeiro, Ediçăo de Desenvolvimento \& Conjuntura, 1961; Hoffmann, Helga. Como planejar nosso desenvoivimento? Rlo de Janeiro, Editôra Civilizaçăo Brasileira, 1963. 
reconhecem a necessidade de um planejamento económico que visa a aumentar a produtividade e desenvolver as riquezas naturais." 16

Foram essas, em sintese, as origens da ideologia e da prática do planejamento governamental no Brasil. Foi uma combinação privilegiada de condições (economia de guerra, perspectivas de desenvolvimento industrial, problemas de defesa nacional, reestruturação do poder político e do estado, nova constelação de classes sociais) que transformou a linguagem e a técnica do planejamento em um componente dinamico do sistema político-administrativo. Ou melhor, a linguagem e a técnica do planejamento foram incorporadas de forma desigual e fragmentária, segundo as possibilidades apresentadas pelo sistema político-administrativo e os interêsses predominantes do setor privado da economia. Esta é a razão por que, ao mesmo tempo que se ensaiava a politica económica governamental planificada, se desenvolvia a controvérsia sôbre os limites da participação estatal na economia.

"No Brasil, a fraqueza e a instabilidade económica nos levaram à adoção de uma série de planejamentos parciais e intervencionismos de estado, sempre reclamados pelos produtores em dificuldades e, quase sempre, mais tarde, por êstes mesmos condenados." 17

16 Conferência das Classes Produtoras do Brasil. Carta económica de Teresópolis. Teresópolis, Estado do Rio de Janeiro, 1-6 de maio de 1945. p. 3 e 4.

17 Simonsen, Roberto C. Op. cit. p. 11 e 12.

\section{OLTIMOS LANÇAMENTOS DA FUNDAÇAO GETOLIO VARGAS}

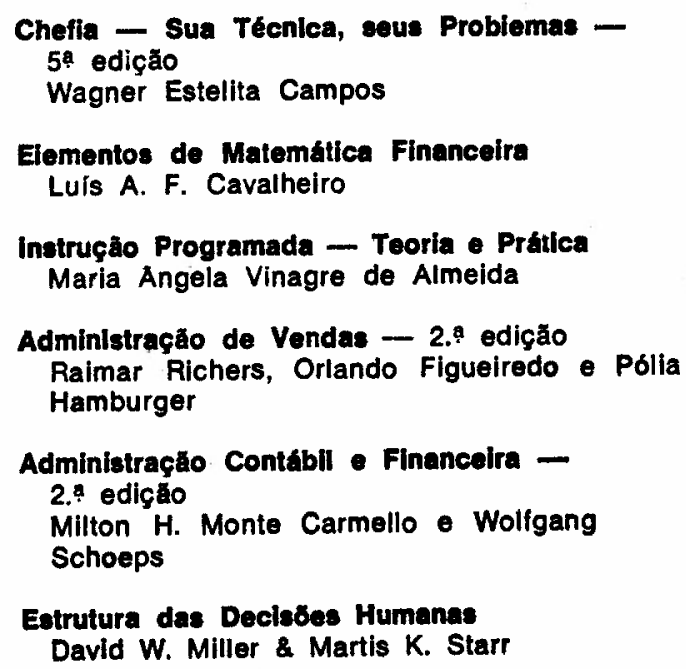

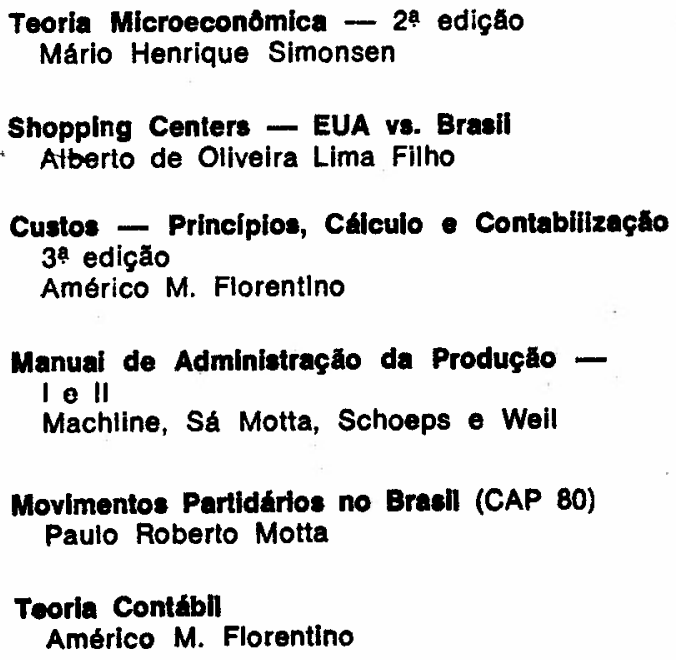

A venda nas principais livrarias ou peio reembôlso postal. Pedidos para a Fundaçăo Getúllo Vargas, Serviço de Pubiicaçóes, Praia de Botafogo, 188, C.P. 21.120, ZC-05, Alo, GB 